\title{
A Study on the Moderating Effect that Value Congruence Influences Organizational Performance*
}

\author{
Joon-Pyo LEE** \\ Received: February 14, 2020 Revised: February 28, 2020 Accepted: March 05, 2020.
}

\begin{abstract}
Purpose - This study examined the relationship between individual creativity and its related variables to observe how individual creativity contributes to organizational performance. In addition, this study strived to explore how to maximize the utilization of individual creativity and innovate the structure of the organization itself so that teams and organizations can respond more effectively to new rising trends. this study aimed to examine whether the value congruence between individuals and organizations (propensity congruence, goal congruence has a significant impact on knowledge sharing and innovation behavior as dependent variables by exerting individual creativity and synergy as independent variables. Research design, data and methodology - SPSS 24.0 program were used to analyze the data. Descriptive Statistics and correlation analysis were performed, and the reliability factor (Cronbach's $\alpha$ ) was calculated. Afterwards, we analyzed the moderating effects of structural equation model analysis and hierarchical regression analysis. The number of samples used in the study were 309 copies. Results - First, Individual creativity had a positive effect on knowledge sharing and innovative behavior. In other words, it was confirmed that decision-making processes fused with individual creativity could create an atmosphere of knowledge sharing and transform the organization. Second, value congruence adjusted the influence of individual creativity on knowledge sharing and innovation behavior. Conclusions - First, it is important for managers to recognize the value and secure the pool of creative talents who will be a potential future basic source of organizational success and competitive advantage. Second, managers should be able to identify those with creative talents and expertise, and use them to increase their knowledge sharing performance, while also developing emotional and motivational creativity. Third, in order improve knowledge sharing performance, managers should pay attention to the emotional aspect of creativity. Fourth, managers should strive to create an environment that is beneficial for the reinforcement of individual self-management capabilities. Fifth, managers should be able to develop decision-making processes to develop potential creativity and encourage creative thinking, opinions, or solutions. Sixth, managers should promote the dissemination and integration of new knowledge based on the creative views and attitudes of team members.
\end{abstract}

Keywords: Individual Creativity, Value Congruence, Knowledge Sharing, Innovation Behavior

JEL Classification Code: D30, M10, M12

\section{1. 서론}

조직의 혁신과 발전을 유형적 목표에 초점을 맞추고 목표치에 도달하였는데도 불구하고 기대했던 효과에 미흡한 경우가 있다. 또한 조직, 기업 간 경쟁이 치열하게 되면서 경쟁자의 유형적인 전략을

*This paper was extracted and developed from Joon-Pyo Lee's Doctor's thesis of Daejeon University (2020)

${ }^{* *}$ First Author, Assistant, Department of Global Trade, Korea National Open University, Korea. Email: rich38@knou.ac.kr

๑) Copyright: Korean Distribution Science Association (KODISA)

This is an Open Access article distributed under the terms of the Creative Commons Attribution NonCommercial License (https://creativecommons.org//icenses/by-nc/4.0/) which permits unrestricted noncommercial use, distribution, and reproduction in any medium, provided the original work is properly cited.
모방함으로써 추구하는 이익이 예상보다 적은 경우를 경험하게 된다. 이것은 조직의 특성 중 그 무엇인가의 무형적인 차별화 요소가 핵심 경쟁력으로서 쉽게 달성하기도 어렵고 모방하기도 어렵다는 점을 증명하는 것이다. 조직의 지식공유와 아이디어 혁신행동은 조직의 성과를 극명하게 구분 짓게 하는 핵심 경쟁 원천이다. 두 개념을 함께 판단해야 하는 이유는 조직이 발전을 위해 궁극적으로 아이디어 혁신을 장려하지만, 이의 촉매제로서 지식공유 문화나 환경이 자리 잡고 있지 않으면 혁신행동은 기대할 수 없기 때문이다. 두 개념의 상관관계가 비교적 높기 때문에 기존 연구에서 두 개념 중 하나만 살펴봄으로써 연구의 실효성을 추구한 것은 타당한 면도 있지만 지식공유가 혁신행동보다 다소 선행하는 면이 있고, 인과관계도 있기 때문에 그 두 
변수의 선행하는 변수가 각각 지식공유와 혁신행동에 어떤 영향을 미치는지 별도로 분석해야 할 필요성이 높다. 따라서 본 연구에서는 두 개념을 기존의 연구와 달리 결과변수로서 병렬적으로 살펴보고 이 두 변수의 원인이 되는 핵심 변수로써 창의성을 선택하였다.

다양한 특성과 이해관계를 가진 조직 구성원들이 서로 시간과 장소가 다른 환경에 놓여 있을 때 개인 및 부서의 이기주의로 조직 전체의 이익에 반하는 위험성이 크다는 점에서 많은 조직이 일률적인 조직 이념, 문화를 강조하는 경우도 있다. 이런 이유로 조직이 다양한 개인의 능력과 의견을 제어하고자 하면서 개인 창의성을 조직의 발전에 반영하지 못하는 문제점이 발생한다. 그러나 의사결정 과정에 대한 개인 창의성의 영향은 조직의 발전에 긍정적 영향을 미친다는 점은 반론의 여지가 없다. 최근에는 어느 수준의 개인 창의성이 팀 의사결정 프로세스와 관련이 있으며 조직 분위기에 영향을 미치는지에 대해 여러 변수를 통해 검증하는 과정에 있다.

본 연구는 조직 구성원들의 개인 창의성이 조직성과에 미치는 영향에서 가치일치성이 어떤 실질적인 기여를 할 수 있는지 찾는 계기가 될 것이다. 개인과 조직의 가치일치성을 통해 팀 및 조직이 새로운 트렌드에 대응하도록 함으로써 조직의 구조 등을 본원적으로 혁신할 수 있는 기회를 갖게 될 것이다.

본 연구의 목적은 다음과 같다.

가치일치성의 구성요소를 재정의한다.

가치일치성이란 어떤 개인이 지각하는 가치와 그 조직이 추구하는 가치가 얼마나 밀접한지의 정도를 나타낸 것이다(Cazier, Shao \& Louis, 2007). 즉, 가치일치성은 말 그대로 개인의 가치와 조직 가치가 일치하는 정도이다. 많은 기존 연구에서 가치일치성 효과가 구성원의 조직몰입이나 직무만족에 긍정적 영향을 미치는 것으로 검증한 바 있다(Bluedom, Kalliath, Strube \& Martin, 1999; Ostroff, Shin \& Kinicki, 2005). 그런데 조직의 가치는 조직의 리더 또는 경영진이 조직 내 구성원들이 공유하기를 바라는 의도성 및 규범성이 있기 때문에 조직의 가치가 내면의 개인 가치와 일치하지 않을 경우 갈등이 발생할 개연성이 상당히 높다. 개인이 이러한 갈등상황을 조직 가치의 강요로 인식할 경우 부정적 감정과 판단을 하게 되는 것은 당연하다. 본 연구에서는 팀이나 조직의 가치와 개인의 가치일치 정도를 판단하는 기준을 현재와 미래의 두 시점으로 구분하여 분석하였다. 즉, 현재 시점의 가치일치성은 개인이 조직이나 팀에 잘 융화되고 조화를 이룰 수 있게 하는 요소로서 '성향 일치성'으로 명명하였다. 또한 미래 시점의 가치일치성은 개인이 조직이나 팀이 제시하는 비전에 대해 동의하는지를 판단하는 요소로서 '목표 일치성'으로 명명하였다. 본 연구에서는 개인 창의성이 조직의 지식공유와 혁신행동에 영향을 미치는 데 있어서 가치일치성은 이를 조절할 수 있는 최적화된 변수로 판단하였다. 가치일치성이라는 개념 자체가 개인과 조직의 두 측면을 포괄하기 때문이기도 하지만 현재 시점의 개인 능력이 조직의 미래
성과로 연결되는 장기간의 과정을 설명해 줄 수 있는 데 적합한 변수이기 때문이다. 창의성이 뛰어난 개인이라도 본인과 조직의 가치 성향이 다르거나 목표가 다르다면 조직 구성원들과 지식을 공유하는 활동은 위축될 것이고 조직 내 혁신적 아이디어가 창출되어 전파하는 데 부정적 영향을 미칠 것이다.

결론적으로 본 연구에서 사용된 4 개의 주요 변수들을 함께 검토한 연구가 기존에 없었다는 점은 본 연구의 차별적 기여가 될 것이다. 특히 창의성이 지식공유와 혁신행동에 긍정적 영향을 미치는 인과관계를 정교하게 설명하여 줄 수 있고, 그 창의성과 시너지 효과를 기대할 수 있는 가치일치성 조절변수를 동시에 고려하였다는 점은 관련 분야에서 최초의 연구이다.

즉 개인과 조직의 가치일치 여부가 조절변수로서 독립변수인 개인 창의성과 시너지 효과를 발휘하여 종속변수인 지식공유와 혁신행동에 획기적인 큰 영향을 미치는지 살펴본다.

\section{2. 이론적 배경}

\section{1. 개인 창의성}

선행 연구에서는 개인 창의성의 하나의 특징, 단일한 요소로서 설명하려는 경향이 있었는데 먼저 개인 창의성의 특징을 전문성으로 보는 견해가 있다.

첫째, 전문성, 즉, 숙련된 기술을 가진 사람들은 조직에서 지식기반을 넓히고, 또한 새로운 위험을 감수할 준비가 되어 있다. 결과적으로 개인은 고도의 유능함과 새로운 혁신에 따른 실패의 위험도 직면할 준비가 되어있기 때문에 새로운 아이디어와 독창성을 발휘하는 것으로 보는 것이다(Momison \& Phelps, 1999).

둘째, 창의성과 관련된 가치를 개인은 상호 간 정보처리방법을 공유하면서 의사소통을 원활히 함으로써 개인의 성과 향상에도 긍정적 영향을 끼친다(Meglino \& Ravlin, 1998). 즉, 개인 창의성은 지적인 영역 이외에 감성 영역의 재능도 의미하는데, 소통되지 않는 창의성은 그 가치를 인정받기 어렵다. 어떤 개인 창의성은 조직이 추구하는 가치와 얼마나 밀접한지, 구성원들에게 얼마나 공감과 동의를 구할 수 있는지에 따라 창의성의 가치가 달라지기 때문이다.

셋째, 창의성 그 자체보다 창의성을 불러일으키는 환경적 요인에 관심이 많은 학자들은 창의성을 내적동기부여(과업추진의지)라고 보고 이를 자신감, 결단력, 신념이라고 해석하였다(Thomas \& Vetthouse, 1990). 그리고 이런 개인의 행동들은 매우 자율적인 환경에서 창의적인 결과물이 나올 수 있다고 한다(Deci, Vallerand, Pelletier \& Ryan, 1991; Spreitzer, 1995). 따라서 이들 견해에서는 자율성에 대한 개인의 인식이 
창의적 결과에 선행한다고 보았다(Amabile, 1988; Amabile, Schatzel, Moneta \& Kramer, 2004). 자율성은 업무에 대한 소유권 및 통제력으로 묘사된다. 개인이 자신의 업무에 책임질 수 있을 때 비로소 위험을 감수하면서 새로운 아이디어를 개발할 준비가 되는 것이 분명하다(Amabile, Conti, Coon, Lazenby, \& Herron, 1996; Scott \& Bruce, 1994). 그러므로 창의성은 개인이 자율적인 업무 프로세스로 촉진되는 업무 환경에서 즐거움을 얻을 때도 증가한다(Amabile et al, 1996),

창의성에 관한 연구는 분석수준에 따라 거시적 수준과 미시적 수준으로 구분되어졌으나, 최근 들어 이런 분석수준을 연결하려는 연구들이 논의되고 있다(Pirola-Merlo \& Mann, 2004). 창의성에 대한 개인의 내부요인과 집단, 조직의 맥락요인 간의 관계를 살핀 Amabile (1983)의 구성요소모델은 개인수준과 집단수준 간의 연결에 있어 중요한 이론 중 하나이다(Pirola-Merlo \& Mann, 2004). Amabile (1988)는 창의성 수준이 현격하게 차이가 나는 결과물 두 개가 있다고 해도 그것들이 동일한 기본 과정을 통해 만들어질 수 있다고 가정하고, 동역학적 시스템 이론(Dynamical Systems Theory)을 적용하여 어떻게 동일한 기본과정이 현격한 질적 차이를 보이는 상이한 결과물들을 이끌어낼 수 있는지를 구성요소모델로 설명하였다. 구성요소모델에 의하면 창의적인 결과물을 만들어 내는 개인의 창의적 행동은 3 가지 구성요소들(전문성, 창의관련작용, 과업동기)의 일치점에서 발생되는 결과이다(Amabile et al, 1996).

\section{2. 지식공유}

Davenport, Davies and Grimes (1998)는 지식경영의 과정을 지식의 획득, 저장, 공유, 활용으로 구분하고, 지식공유는 개인적 차원의 지식 습득이나 학습이 아닌 조직적 차원의 활동이라고 정의한 바 있고, 따라서 지식공유는 조직 구성원이 개인적 차원에서 학습하는 과정이 아니라 조직 차원에서 이를 공유하고 전파하는 사회적 활동이라고 할 수 있다.

지식공유를 통해서 조직은 지식에 기초한 자원을 개발하고 투자할 수 있다(Wang \& Noe, 2010). 최근의 연구는 지식공유의 선행요인으로서 환경적 요인과 동기적 요인으로 나누고 있는데 환경적 요인은 조직의 구조와 경영진의 지원과 같은 조직의 맥락 프로세스와 팀의 성격 그리고 조직문화의 성격이 거론된다. 이에 비해서 동기적 요인으로는 팀원에 대한 신뢰와 조직에 대한 태도, 사회적 비용과 같은 요인을 들 수 있다(Abrams, Cross, Lesser \& Levin, 2003; Riege, 2005). 다른 요인으로서는 지식공유의 맥락을 들 수 있는데 팀 내 지식공유처럼 동일한 목적을 향해서 상호협조적인 관계일 때 지식공유는 증가하지만 조직 간, 부서 간의 관계와 같이 경쟁적인 관계일 때에는 자발적인 지식공유를
기대하기 어렵다. 다시 말해서 환경적인 맥락이 구성워 간의 경쟁을 유도하느냐 협력을 요구하느냐에 따라서 지식공유의 정도가 달라진다.

최근 연구들은 지식의 공유를 촉진하는 요인과 방해하는 요인으로 나누고 있다(Riege, 2005). 먼저 지식의 공유를 방해하는 요인을 살펴보면 환경적인 요인으로서 인정과 보상과 같은 인센티브의 부족이 중요한 요인으로 거론되고 있으며 개인적 요인으로는 다양한 이유로 지식을 축적하려는 강한 동기가 언급되고 있는데 구성원 간의 신뢰의 부족도 개인적으로 지식을 축적하려는 동기를 강화한다(Bock, Zmud, Kim, \& Lee, 2005).

\section{3. 혁신행동}

혁신행동(Innovative Behavior)은 "새로운 아이디어를 채택하고 확산하며 실천하는 행동"(Scott \& Bruce, 1994)과 "문제의 인식과 새로운 아이디어 및 해결책의 생성, 그리고 그 아이디어의 실현을 위한 후원을 얻기 위하여 지지자들의 연합을 구축하고, 이를 통하여 혁신을 위한 시제품을 만드는 것"Kanter, 1988)으로 된다.

혁신은 변화로부터 기대되는 혜택을 이끌어내기 위한 의도적 시도로서, 기대되는 혜택의 범위는 경제적인 것에서부터 개인의 성장, 만족의 증진, 집단 응집력, 대인 간 의사소통 개선 등을 포함하는 매우 포괄적 개념이다. 혁신행동은 새로운 아이디어, 절차, 제품을 집단 및 조직에 의도적으로 도입하고 적용하는 것이다(West \& Farr, 1989). Farr and Ford (1990)는 조직 구성원이 자신의 역할과 관련된 새롭고 유용한 아이디어, 절차, 제품을 의도적으로 도입하는 행위를 과업역할 혁신으로 정의하였다. Scott and Bruce (1994)는 자신의 과업역할이나 소속집단 또는 조직의 성과 향상에 도움이 되는 새로운 아이디어를 의도적으로 참조 도입, 적용하는 활동을 의미하는 혁신적 과업행동이라는 개념을 제시하였다. 혁신행동은 창의성과 구별되는 개념으로 창의성은 새롭고 유용한 아이디어 개발에 초점을 맞추고 있지만 혁신행동은 아이디어 개발 뿐 아니라 그것을 홍보, 실행 및 확산 시키는 과정을 모두 포괄하는 개념이다. 어떠한 영역에서든 구성원들의 혁신적 행동은 새롭고 유용한 아이디어를 찾아내는 과정에서부터 출발하게 된다(Amabile et al, 1996; 1988; Woodman, Sawyer, \& Griffin, 1993).

지식과 정보가 가치를 창출하는 핵심요소로 자리 잡게 되면서 창의적인 아이디어를 통해 더 높은 가치를 창출하는 것이 기업의 생존과 경쟁력 확보의 관건이 되고 있다(Daellenbach, McCarthy, \& Schoenecker, 1999; Scott \& Bruce, 1994).

혁신행동은 창의성과는 달리 아이디어의 개발과 실행을 포함하는 과정이며, 개인이 문제 및 변화의 필요성을 인식하여 변화의 과정을 주도하는 문제의 인식 및 아이디어 창출, 개발, 수용, 실천 및 확산의 과정으로 이루어져 있다(Amabile et al, 1996; Scott \& Bruce, 1994). 속도가 
빠르고 불연속적이며 불확실성이 높은 기술 환경의 변화를 감안할 때 문제탐색과 해결을 위한 혁신적 아이디어의 개발, 실현, 확산 등과 같은 조직 구성원들의 자발적이며 역할 외적 노력 없이는 조직의 경쟁력 강화를 기대하기 어려울 것이다(Oldham \& Cummings, 1996; Shalley, 1995). 조직 내에서 혁신이 성공하기 위해서는 실행 주체인 구성원의 역할과 태도가 중요하다. 조직 구성원들이 다양한 아이디어를 개발하고 적용하는 혁신활동들에 능동적으로 참여할 때 조직수준에서의 혁신활동이 일어나게 되는 것이다. 직무수행과정에서 자율성을 부여하면 구성원들은 스스로 목표를 설정하고 목표달성을 위한 아이디어를 제안하고 적극적 과업 수행을 통해 문제를 해결하는 성향을 보인다(Bandura \& Locke, 2003). 반면 업무에 대한 자율성을 보장받지 못하면 직무스트레스는 증가하고 직무만족은 감소하게 된다.

\section{4. 가치일치성}

가치일치성(Nalue Congruence)은 Spreng, MacKenzie and Olshavsky (1996)가 제시한 "일치성" 개념에 기반하고 있는데, 조직 리더와 구성원 사이의 개인적 가치가 얼마나 적합한지 혹은 서로 유사한지를 나타내는 것이다(Jung, Yammarino \& Lee, 2009). 또한 어떤 개인이 지각하는 가치와 그 조직이 추구하는 가치가 얼마나 밀접한지의 정도를 나타낸 것으로서 가치일치성이라고도 한다(Cazier et al, 2007). 조직에서 개인이 중요하다고 인식하는 가치와 다른 과업이 주어질 때, 내적 불만족 등의 부정적 감정을 경험하면서 특정한 환경이나 상황에서 부정적 태도와 행동을 보이는 것이다. 조직관리 차원에서 구성원의 선발과정과 조직사회화 과정에 많은 자원을 투입하여 조직의 가치와 개인 가치가 조회될 수 있도록 노력을 기울이는 이유가 여기에 있다(Chatman, 1989). 조직의 가치는 두 가지 측면을 고려할 수 있는데 하나는 조직이 지향하는 가치와, 다른 하나는 조직 구성원이 공유하는 가치이다.

첫째, 조직이 지향하는 가치는 조직 경영진이 조직 내 구성원들에게 인식시키고 뿌리내리기를 바라는 미래지향적 가치를 말하며, 이를 의도된 가치(Intended Value)로도 표현한다. 둘째, 조직 구성원이 공유하는 가치는 조직 내에 존재하는 가치(Existing Value)로서 조직문화와는 긴밀하게 연계되는 중요한 요소이다(Rousseau, 1995).

가치일치를 다음과 같이 3 가지 측면으로 나누어 볼 수 있다. 첫째, 개인과 조직의 가치일치(Person-Organization Fit)이다. 개인이 지각하는 가치관이 있고 마찬가지로 조직도 조직이 필요로 하는 가치관이 존재하며 동일한 조직에서 함께 근무하는 구성원들도 서로 다른 가치관을 가지고 직무수행을 할 수 있으므로 이러한 가치가 항상 일치하지는 않는다. 따라서 개인과 조직은 그 가치관이 서로 일치하는지의 정도에 따라 조직에 대한 구성원의 태도와 행동이 달라지며, 그로 인하여 조직성과에 영향을 미치게 된다. 개인 가치는 각
개인의 태도와 행동의 방향에 영향을 주는 나침판과 같은 역할을 한다. 개인과 조직은 상호작용을 하면서 서로 영향을 교환하게 되며 개인 가치와 조직 가치의 일치정도가 높을수록 조직은 지속 가능성이 높아지고 조직 구성원들은 상호관계를 통해서 직무만족도와 직무몰입이 높아진다. 이로써 조직의 공동목표달성을 위해 서로 협력적 노력을 기울이는 등 조직경영활동 전반에 걸쳐 광범위하게 영향을 준다(Hunt, Wood, \& Chonko, 1989). 둘째, 개인과 팀의 가치일치(PersonTeam Fit)이다. 이는 개인 가치와 개인이 소속되어 있는 팀과의 가치일치 정도를 말한다. 개인은 팀에 소속되므로 팀별 과업과 특성에 따라 팀 가치에 영향을 주기도 하고 또, 팀 가치의 영향을 받기도 한다. 개인과 팀 가치가 일치할수록 팀의 성과 향상에 긍정적 영향을 주고 조직 전체의 변화를 이끌기도 한다. 조직 전체의 관점에서 보면 팀은 조직의 하위조직으로서 조직 가치와는 상이한 가치를 가질 수 있으므로 팀 운영의 자율성을 해치지 않으면서도 조직 관리의 일관성이 유지되도록 하는 조직의 경영관리 활동이 필요하다. 셋째, 개인과 직무의 가치일치(Person-Job Fit)이다. 이는 개인 가치와 개인이 수행하는 직무가치 간의 일치 정도를 나타내는 것으로써, 개인의 과업수행능력과 직무가 요구하는 내용 간의 일치 정도 또는 개인의 희망과 직무속성 간의 일치 정도라고도 할 수 있다. 개인-직무 간의 일치는 과업수행능력과 관련된 심리적사회적 욕구충족과 직무요구에 따른 과업수행 행동 사이를 중재하는 표준과 의사결정 과정의 지침으로 작용하면서 직무수행의 지속성 증진에 긍정적인 영향을 준다.

조직 구성원들과 조직문화 간의 가치일치는 구성원들의 조직몰입에 있어 긍정적인 관계를 가진다(Chatman, 1989). 내재적 가치는 조직 구성원들의 동기부여에 중요한 메커니즘으로 작용할 수 있기 때문에 가치일치는 조직이 조직성과를 향상시키는데 중요한 역할을 한다. 조직의 가치와 유사한 가치를 가진 개인은 상호간 정보처리방법을 공유하면서 의사소통을 원활히 함으로써 개인의 성과 향상에도 긍정적 영향을 끼친다(Meglino \& Ravlin, 1998). 조직 구성원들 간의 공유된 가치에 관해서는 많은 연구자들에 의해 조직에 대한 주요이슈로 연구된 바 있으며 조직 내에서 개인과 조직의 가치일치성과 효과 간에 긍정적 유의미한 연관성이 있다.

조직의 가치에 대한 명확한 이해는 구성원들의 직무에 대한 적응력과 조직몰입 및 조직에 대한 만족수준을 제고시킨다(Meglino \& Ravlin, 1998).

\section{3. 연구가설}

가치일치성은 개인 창의성과 지식공유와의 관계, 개인 창의성과 혁신행동의 관계를 강화시켜서 지식공유와 혁신행동의 성과를 더욱 긍정적 방향으로 증가시키는 반면, 부정적 영향을 완화시키는 역할을 
한다. 연구자는 이미 개인 창의성이 지식공유와 혁신행동에 각각 긍정적 영향을 미치는 점은 선행연구에서 밝힌 바 있다. 따라서 본 연구에서는 가치일치성 변수의 조절적 역할에 중점을 두고 분석하였다(Lee \& Park, 2019).

가치일치성 변수는 본래 단독으로도 지식공유와 혁신행동에 영향을 미칠 수 있는 원인 변수(독립변수)이다. 그럼에도 불구하고 가치일치성 변수를 조절변수로써 검증하고자 하는 것은 가치일치의 문제는 조직의 과업환경과 조직문화의 요소로서 조직 리더나 경영자가 노력에 의해 개선될 수 있는 여지가 있기 때문이다. 즉, 개인 창의성은 개인의 고유 영역이자 내면의 문제로서 조직이 어떤 영향을 미치기에는 한계가 있는 반면에 가치 일치성은 조직의 노력에 따라 개인의 가치와 조직의 가치의 간극을 좁힐 수 있는 가능성이 충분하기 때문이다.

개인과 조직의 가치일치성이 높을수록 개인 창의성이 지식공유와 혁신행동에 미치는 영향을 긍정적 방향으로 시너지 효과를 일으키면서도 개인 창의성의 부족한 부분을 가치일치성이 보완하는 것으로 판단된다. 즉, 가치일치성 여부에 따라 개인 창의성이 지식공유와 혁신행동에 미치는 영향은 달라질 수 있을 것이다. 이러한 논리를 바탕으로 다음의 <가설 1>과 <가설 2>를 설정하였다.

가설 1: 개인 창의성과 지식공유 간의 관계를 가치일치성이 조절할 것이다.

1-1: 개인 창의성의 전문성과 지식공유 간의 관계를 가치일치성이 조절할 것이다.

1-2: 개인 창의성의 감성지능과 지식공유 간의 관계를 가치일치성이 조절할 것이다.

1-3: 개인 창의성의 내적 동기부여와 지식공유 간의 관계를 가치일치성이 조절할 것이다.

가설 2: 개인 창의성과 혁신행동 간의 관계를 가치일치성이 조절할 것이다.

2-1 개인 창의성의 전문성과 혁신행동과의 관계를 가치일치성이 조절할 것이다.

2-2: 개인 창의성의 감성지능과 혁신행동과의 관계를 가치일치성이 조절할 것이다.

2-3: 개인 창의성의 내적 동기부여와 혁신행동과의 관계를 가치일치성이 조절할 것이다.

\section{4. 연구의 방법.}

\section{1. 연구대상}

연구를 수행하기 위해 사기업, 공기업, 공공기관 등 다양한 기관에 재직중인 근로자를 모집단으로 설정하였다. 조사 기간은 2019 년 6 월 초부터 8 월 말까지 약 2 개월 정도로 진행하였으며, 350 부의 설문지를 배포하고, 317 부를 회수하여 회수율은 $90.6 \%$ 이다. 표본추출은 편의 추출법을 사용하였고 근로자들의 자기기입식방법으로 총 317 부의 표본을 얻었다. 다수의 결측치가 존재하는 응답과 불성실한 설문 8 부를 제외하고 309 부의 유효한 표본을 분석에 사용하였다. 성별은 남성 195 명(63.1\%), 여성 113 명(36.9\%), 기혼 206 명(66.7\%), 미혼 103 명(33.3\%), 연령은 30 대 102 명(33.0\%)로 가장 많았으며 40 대 90 명(29.1\%), 50 대 이상 82 명(26.5\%), 20 대 35 명(113\%)로 나타났다. 학력은 대졸 152 명(49.2\%)로 가장 많았으며 대학원졸 이상 57 명(18.4\%), 전문대졸 55 명(17.8\%), 고졸 이하 45 명(14.6\%)로 나타났다. 근속연수는 15 년 이상 106 명(34.8\%), 10 14 년 59 명(19.3\%), 5 9 년 62 명(20.3\%), 1 4 년 52 명(17.0\%), 1 년 미만 26 명(8.5\%)로 나타났다. 기업규모로 종업원 수는 100 인 이상 153 명(50.0\%), 1 20 인 86 명(28.1\%), 21 50 인 52 명(17.0\%), 51 99 인 15 명(4.9\%)로 나타났다. 업종은 기타 137 명(44.3\%), 제조업 67 명(217\%), 서비스업 93 명(30.1\%), 금융업 12 명(3.9\%), 근무기관은 사기업 137 명(44.6\%), 공공기관 86 명(28.0\%), 기타 56 명(18.2\%), 공기업 28 명(9.1\%)로 나타났다.

\section{2. 변수의 조작적 정의 및 측정도구}

\subsection{1 개인 창의성}

개인 창의성의 조작적 정의는 특정시기에 사람들에게 인정받거나 만족을 주거나 지지를 받는 참신하고 유용한 산물의 창출로 정의한다. 개인 창의성의 측정항목은 (Fammer, Tiemey \& Kung-Maintyre, 2003; Tiemey \& Famer, 2002) 문항을 번안하여 사용한다. 질문 문항은 '나는 항상 당면한 문제에 대한 대체적인 해결법을 고려한다.' '팀 구성원들이 동일한 목표를 위해 일하게 만든다.' '새로운 상황은 두려움보다 도전하고 싶은 마음을 만든다.' 등 총 28 개 문항을 통해 리커트 5 점 척도로 측정한다. 설문 문항을 통해 개인 창의성의 구성 하위 요인으로서 전문성(기술, 경험), 감성지능(소통 능력), 내적 동기부여(과업추진의지) 등 3 요인을 추출하였다.

\subsection{2 지식공유}

지식공유의 조작적 정의는 과업정보 및 노하우를 제공하여 동료를 돕거나 문제해결 아이디어 창출 및 수행에 있어 협력하는 것이라고 정의한다. 지식공유의 측정항목은 Davenport et al. (1998)과 Gupta and Govindarajan (2000)의 문항을 번안하여 사용한다. 질문 문항은 '우리 회사 구성원들은 회사 밖의 회의, 세미나, 교육 등에서 필요한 정보와 지식을 
습득한다.' '우리 회사 사원들 개개인의 노하우나 지식, 정보 등을 체계적으로 만들어 내고 있다.' '우리 회사 사원들은 개인별로 습득한 노하우를 업무 수행에서 서로 공유하기 위해 노력한다.' 등 15 개 문항을 리커트 5점 척도로 측정한다. 설문 문항을 통해 지식공유의 구성 하위 요인으로서 지식의 창출, 지식의 조직화, 지식의 활용 등 3 요인을 추출하였다.

\subsection{3. 혁신행동}

혁신행동의 조작적 정의는 개인이 문제 및 변화의 필요성을 인식하여 변화의 과정을 주도하는 문제의 인식 및 아이디어 창출, 개발, 수용, 실천 및 확산의 과정으로 정의한다. 혁신행동의 측정도구는 Janssen (2000)과 Kleysen and Street (2001)의 문항을 번안하여 사용한다. 질문 문항은 '나는 업무 관련된 독창적 방법을 고안해 낸다.' '나는 어려운 문제를 해결하기 위해 새로운 아이디어를 개발한다.' '나는 업무수행을 위한 새로운 기술, 도구, 방법 등을 찾으려고 애슨다.' 등 9 개 문항을 리커트 5 점 척도로 측정한다. 설문 문항을 통해 혁신행동의 구성 하위 요인으로서 아이디어 도출, 아이디어 실행, 아이디어 촉진 등 3 요인을 추출하였다.

\subsection{4. 가치일치성}

가치일치성의 조작적 정의는 조직 가치와 개인 가치의 일치정도를 나타낸다고 정의한다. 가치일치성의 측정항목은 Cable and Judge (1996)가 개발한 지각된 개인-조직 가치의 일치 스케일을 가치일치의 측정도구로 사용한다. 질문 문항은 '내 성격은 우리 조직 이미지와 잘 맞는다.' '우리 조직은 나와 잘 맞고 내가 필요로 하는 것을 충족시킨다.' '나는 우리 조직의 경영이념을 잘 알고 실천하고 있다.' '나 자신이 추구하는 가치는 우리 팀원이 추구하는 가치와 잘 맞는다.' '내가 추구하는 가치는 우리 조직이 추구하는 가치와 잘 맞는다.' '나는 우리 조직이 추구하는 목표와 비슷한 목표를 가지고 있다.' 등의 8 개 문항을 리커트 5 점 척도로 측정하여 두 개의 구성요소에 대해서 측정한다. 설문 문항을 통해 가치일치성의 구성 하위 요인으로서 성향 일치성(현재 융화), 목표 일치성(미래 비전) 등 3 요인을 추출하였다.

\section{5. 연구결과 및 해석}

\section{1. 측정 변인의 탐색적 요인 분석}

측정변인 타당도 검정을 위하여 SPSS 24.0 프로그램을 활용하여 탐색적 요인분석(Exploratory Factor Analysis. EFA)을 실시하였다. 탐색적 요인분석은 측정도구의 타당성과 각 변인의 고유한 특성을 측정하는가를 알아보기 위하여 실시한다. 탐색적 요인분석의 요인
추출은 주성분 분석(Principal Components Analysis)방법으로 Eigen Value 값 1 을 기준으로 각 요인들의 타당성 검정을 위한 요인을 추출하였다. 또한 베리맥스 직교회전방식을 채택하여 요인적재량(Factor Loading)을 단순화 하였다. $\mathrm{KMO}$ (Kaiser-Meyer-Olkin) 값과 주성분 분석의 추출 요인에 의한 설명비율로 공통성(Communality)을 산출하여 변수들 간의 상관관계의 설명력을 검정하였다. 본 연구는 요인적재량 .40 이하의 항목은 제거하여 요인분석을 실시하였다.

개인 창의성의 요인분석 결과 국'내외 선행연구와 같이 3 개의 하위 요인이 추출되었다. 그러나 요인부하량이 50 보다 낮게 나타난 문항은 제거하였다. 1 요인은 전문성, 2 요인은 감성지능, 3 요인은 내적동기부여로 명명하였다. 전문성의 요인부하량은 .539 .792 의 범위를, 감성지능의 요인부하량은 $\quad .534$.774 의 범위를, 내적동기부여는 .569 .663의 범위를 나타낸다. 요인설명력은 요인 1 은 11183 , 요인 2는 6.793 , 요인 3 은 5.402 로 나타남에 따라 개인 창의성을 충분히 설명하고 있다. 공통성은 모두 기준치인 .40 이상으로 개인 창의성의 항목별 요인의 타당도가 확보되었다. 또한 누적분산설명력은 $50.820 \%$, 표본의 $\mathrm{KMO}$ 지수는 .950 으로 요인분석에 적합한 자료인 것으로 분석되었다.

가치일치성의 요인분석 결과 국내외 선행연구와 같이 2 개의 하위 요인이 추출되었다. 그러나 요인부하량이 50 보다 낮게 나타난 문항은 제거하였다. 1 요인은 성향 일치성, 2 요인은 목표 일치성으로 명명하였다. 성향 일치성의 요인부하량은 .771 .880 의 범위를, 목표 일치성의 요인부하량은 .757 .866 의 범위를 나타낸다. 요인설명력은 요인 1 은 45.513, 요인 2 는 30.440 으로 나타남에 따라 개인 창의성을 충분히 설명하고 있다. 공통성은 모두 기준치인 .40 이상으로 개인 창의성의 항목별 요인의 타당도가 확보되었다. 또한 누적분산설명력은 $75.954 \%$, 표본의 $\mathrm{KMO}$ 지수는 .914 으로 요인분석에 적합한 자료인 것으로 분석되었다.

지식공유의 요인분석 결과 국내외 선행연구와 같이 3 개의 하위 요인이 추출되었다. 그러나 요인부하량이 50 보다 낮게 나타난 문항은 제거하였다. 1 요인은 지식창출, 2 요인은 지식 조직화, 3 요인은 지식활용으로 명명하였다. 지식창출의 요인부하량은 .828 .723 의 범위를, 지식 조직화의 요인부하량은 .693 .833 의 범위를, 지식활용은 .694 .827 의 범위를 나타낸다. 요인설명력은 요인 1 은 32.559 , 요인 2 는 29.011, 요인 3 은 13.204 로 나타남에 따라 지식공유를 충분히 설명하고 있다. 공통성은 모두 기준치인 40 이상으로 지식공유의 항목별 요인의 타당도가 확보되었다. 또한 누적분산설명력은 $74.774 \%$, 표본의 $\mathrm{KMO}$ 지수는 .946 으로 요인분석에 적합한 자료인 것으로 분석되었다.

혁신행동의 요인분석 결과 국내외 선행연구와 같이 3 개의 하위 요인이 추출되었다. 그러나 요인부하량이 50 보다 낮게 나타난 문항은 제거하였다. 1 요인은 아이디어 도출, 2 요인은 아이디어 실행, 3 요인은 
아이디어 촉진으로 명명하였다. 아이디어 도출의 요인부하량은 .696 .830 의 범위를, 아이디어 실행의 요인부하량은 .710 .740의 범위를, 아이디어 촉진은 .693 .847의 범위를 나타낸다. 요인설명력은 요인 1 은 32.574, 요인 2 는 22.010, 요인 3 은 20.477 로 나타남에 따라 혁신행동을 충분히 설명하고 있다. 공통성은 모두 기준치인 .40 이상으로 개인 창의성의 항목별 요인의 타당도가 확보되었다. 또한 누적분산설명력은 $75.062 \%$, 표본의 $\mathrm{KMO}$ 지수는 .948으로 요인분석에 적합한 자료인 것으로 분석되었다.

\section{2. 측정 변인의 타당성 검증}

측정모형의 변인 별 타당성 검정을 위하여 수렴 타당성(Convergent Validity)과 판별 타당성을 검정하였다. 수렴 타당성 검정은 개념신뢰도(Construct Reliability. CR)값을 활용하였고, 판별 타당성 검정은 평균분산추출(Average Vaniance Extracted: AVE)값으로 평가하였다.

Table 1: Validity Test Result of Measurement Model ( $n=309)$

\begin{tabular}{|c|c|c|c|c|}
\hline Variable & $\begin{array}{l}\text { Individual } \\
\text { Creativity }\end{array}$ & $\begin{array}{c}\text { Value } \\
\text { Congruence }\end{array}$ & $\begin{array}{l}\text { Knowledge } \\
\text { Sharing }\end{array}$ & $\begin{array}{c}\text { Innovation } \\
\text { Behavior }\end{array}$ \\
\hline $\begin{array}{l}\text { Individual } \\
\text { Creativity }\end{array}$ & 1 & & & \\
\hline $\begin{array}{c}\text { Value } \\
\text { Congruence }\end{array}$ & $\begin{array}{c}.411 \\
.168 \\
(.015)\end{array}$ & 1 & & \\
\hline $\begin{array}{c}\text { Knowledge } \\
\text { Sharing }\end{array}$ & $\begin{array}{c}.519 \\
.269 \\
(.015)\end{array}$ & $\begin{array}{c}.671 \\
.450 \\
(.014)\end{array}$ & 1 & \\
\hline $\begin{array}{c}\text { Innovation } \\
\text { Behavior }\end{array}$ & $\begin{array}{c}.763 \\
.582 \\
(.012)\end{array}$ & $\begin{array}{c}.476 \\
.226 \\
(.014)\end{array}$ & $\begin{array}{c}.624 \\
.389 \\
(.012)\end{array}$ & 1 \\
\hline AVE & .916 & .905 & .909 & .918 \\
\hline CR & .967 & .964 & .966 & .969 \\
\hline
\end{tabular}

* In order of correlation coefficient, squared correlation coefficient, and standard error of covariance (S.E.)
측정모형의 타당성 검정결과는 <Table 1 >과 같다. 5 개 변인의 평균분산추출지수(AVE)은 $\quad .50 \quad$ 이상으로(.905 .918) 판별타당도가 확보되었다. 또한 개념신뢰도값(CR)이 .70 이상으로(.964 .969) 나타나 수렴타당도가 확보되었다. 변인들의 상관계수의 제곱 값이 각 변인의 평균분산추출(AVE)보다 작은 것으로 나타났다. 분석결과 변인별 판별타당성이 확보되었음을 알 수 있다.

측정모형의 판별타당성을 확인한 결과는 <Table 2>와 같다. 상관계수 $\pm 2 \times$ 표준오차의 값이 모두 .325 .849 로 신뢰구간 1 을 넘지 않는다. 따라서 측정모형의 판별타당성이 확보되었다.

Table 2: Discriminant Validity of Measurement Model $(\mathrm{n}=309)$

\begin{tabular}{|c|c|c|c|c|}
\hline Variable & $\begin{array}{l}\text { Individual } \\
\text { Creativity }\end{array}$ & $\begin{array}{c}\text { Value } \\
\text { Congruence }\end{array}$ & $\begin{array}{l}\text { Knowledge } \\
\text { Sharing }\end{array}$ & $\begin{array}{c}\text { Innovation } \\
\text { Behavior }\end{array}$ \\
\hline $\begin{array}{l}\text { Individual } \\
\text { Creativity }\end{array}$ & $\begin{array}{l}.726 \\
.554\end{array}$ & & & \\
\hline $\begin{array}{c}\text { Value } \\
\text { Congruence }\end{array}$ & $\begin{array}{l}.497 \\
.325\end{array}$ & $\begin{array}{l}.542 \\
.370\end{array}$ & & \\
\hline $\begin{array}{l}\text { Knowledge } \\
\text { Sharing }\end{array}$ & $\begin{array}{l}.605 \\
.433\end{array}$ & $\begin{array}{l}.670 \\
.498\end{array}$ & $\begin{array}{l}.757 \\
.585\end{array}$ & \\
\hline $\begin{array}{l}\text { Innovation } \\
\text { Behavior }\end{array}$ & $\begin{array}{l}.849 \\
.677\end{array}$ & $\begin{array}{l}.709 \\
.537\end{array}$ & $\begin{array}{l}.562 \\
.390\end{array}$ & $\begin{array}{l}.710 \\
.538\end{array}$ \\
\hline
\end{tabular}

* (Correlation coefficient $+2 \times$ standard error), (correlation coefficient- $2 \times$ standard error)

\section{3. 측정 변인의 신뢰도 검증}

탐색적 요인분석을 통해 추출된 요인들의 문항 간 내적 일관성을 확인을 위하여 Cronbach's $\alpha$ 계수를 산출하였다. 측정변인의 신뢰도는 측정한 다변량 변수 사이의 일관된 정도를 의미한다. 동일 개념을 반복적으로 측정했을 때 일정한 결과가 나오면 안정성이 높다고 할 수 있다. 분석결과 <Table 3>과 같다. Cronbach's $\alpha$ 계수는 .740 .952 로 산출되어 측정도구의 신뢰도가 확보되었음을 확인하였다.

Table 3: Reliability Analysis of Measurement Variables $(n=309)$

\begin{tabular}{|c|c|c|c|c|c|}
\hline variable & Measurement variable & Item count & $\begin{array}{c}\text { Cronbach's } \alpha \\
\text { When removing items }\end{array}$ & $\begin{array}{c}\text { First item } \\
\text { number }\end{array}$ & Items removed \\
\hline \multirow{3}{*}{ Individual Creativity } & Professionalism & 16 & .916 & \multirow{3}{*}{46} & \multirow{3}{*}{18} \\
\hline & Emotional Intelligence & 7 & .916 & & \\
\hline & Internal Motivation & 5 & .917 & & \\
\hline \multirow{2}{*}{ Value Congruence } & Propensity Congruence & 3 & .920 & \multirow[b]{2}{*}{9} & \multirow[b]{2}{*}{1} \\
\hline & Goal Congruence & 5 & .917 & & \\
\hline Knowledge Sharing & Creation of knowledge & 2 & .917 & 15 & - \\
\hline
\end{tabular}




\begin{tabular}{|c|c|c|c|c|c|}
\hline & Organization of knowledge & 6 & .915 & \multirow{2}{*}{} \\
\cline { 2 - 5 } & Use of knowledge & 7 & .909 & \\
\hline \multirow{3}{*}{ Innovation Behavior } & Derivation of ideas & 4 & .911 & \multirow{2}{*}{12} \\
\cline { 2 - 5 } & Execution of ideas & 2 & .913 & \\
\cline { 2 - 5 } & Promotion of ideas & 3 & .912 & \\
\hline
\end{tabular}

\section{4. 가치일치성의 조절효과}

개인 창의성과 지식공유 및 혁신행동의 관계에서 가치일치성의 조절효과를 검증하기 위해 위계적 회귀분석을 실시하였다. 조절효과를 검증하기 위해 종속변수로 지식공유와 혁신행동을 투입한 뒤 위계적 회귀분석의 1 단계에서 인구통계학적 변인(성별, 연령, 결혼여부, 학력,
업종)을 투입하여 그 영향을 통제하였다. 2 단계에서는 개인 창의성을 투입하였으며, 3 단계에서는 조절변수인 가치일치성을, 4 단계에서는 독립변수와 조절변수의 상호작용 항을 투입하였다. 조절효과에 대한 해석의 용성과 다중공선성의 문제를 최소화하기 위하여 독립변수와 조절변수를 평균중심화(Mean Centening)하여 분석하였다.

Table 4: Moderating Effect of Value Congruence on Knowledge Sharing

\begin{tabular}{|c|c|c|c|c|c|c|c|}
\hline \multirow{2}{*}{\multicolumn{2}{|c|}{ Variables }} & \multicolumn{5}{|c|}{ Knowledge Sharing (B) } & \multirow{3}{*}{ VIF } \\
\hline & & \multirow{2}{*}{ Step 1} & \multirow{2}{*}{ Step 2} & \multirow{2}{*}{ Step 3} & \multirow{2}{*}{ Step 4} & \multirow{2}{*}{$\frac{\mathbf{t}}{1.451}$} & \\
\hline \multirow{9}{*}{ Control Variables } & (Constant) & & & & & & \\
\hline & Gender & .060 & .152 & .130 & .130 & $2.970 * * *$ & 1.300 \\
\hline & Marital Status & -.058 & -.085 & -.033 & -.034 & -.651 & 1.861 \\
\hline & Age & -.113 & -.170 & -.160 & -.171 & $-2.983 * * *$ & 2.231 \\
\hline & Education & .145 & .045 & .013 & .012 & .282 & 1.193 \\
\hline & Working Years & .049 & .092 & .087 & .087 & 1.538 & 2.161 \\
\hline & Number of Employees & .011 & -.037 & .042 & .048 & 1.124 & 1.221 \\
\hline & Type of Business & .023 & .066 & -.011 & -.021 & -.463 & 1.401 \\
\hline & Working Organization & .018 & .031 & .047 & .062 & 1.367 & 1.374 \\
\hline \multirow{3}{*}{$\begin{array}{l}\text { Independent Variable } \\
\text { : Individual Creativity }\end{array}$} & $\begin{array}{l}\text { Professionalism } \\
\text { ( I -1) }\end{array}$ & & .213 & .171 & .275 & 1.447 & 2.481 \\
\hline & $\begin{array}{l}\text { Emotional Intelligence } \\
\text { ( I -2) }\end{array}$ & & .371 & .202 & -.119 & -.741 & 1.618 \\
\hline & $\begin{array}{c}\text { Internal Motivation } \\
\text { ( I -3) }\end{array}$ & & .123 & .049 & .117 & .674 & 2.315 \\
\hline Moderationg Variables & Value Congruence(III) & & & .535 & .511 & $11.183 * * *$ & 1.416 \\
\hline \multirow{3}{*}{ Interaction Terms } & ( I -1*III) & & & & -.107 & -.538 & 2.972 \\
\hline & $(\mathrm{I}-2 * \mathrm{III})$ & & & & .352 & $2.083^{*}$ & 1.378 \\
\hline & $(\mathrm{I}-3 * \mathrm{III})$ & & & & -.084 & -.455 & 2.151 \\
\hline \multicolumn{2}{|c|}{$\mathrm{R}^{2}$} & .033 & .353 & .572 & .578 & & \\
\hline \multicolumn{2}{|c|}{ Adjusted $\mathrm{R}^{2}$} & .006 & .328 & .554 & .556 & & \\
\hline \multicolumn{2}{|c|}{$\Delta \mathrm{R}^{2}$} & .033 & .320 & .219 & .006 & & \\
\hline \multicolumn{2}{|c|}{$\mathrm{F}$} & 1.239 & $14.380 * * *$ & $32.161^{* * * *}$ & $26.144 * * *$ & & \\
\hline
\end{tabular}

$* \mathrm{p}<.05 * * * \mathrm{p}<.001$ 
<가설 $1>$ 개인 창의성과 지식공유 간의 관계를 가치일치성이 조절할 것이다. 라는 가설을 검증하기 위하여 <Table 4>와 같이 위계적 회귀분석을 실시하였다. 3 단계 모형은 개인 창의성과 지식공유 간의 관계에서 가치일치성의 조절효과를 검증하기 위해, 개인 창의성의 하위차원과 가치일치성을 곱한 상호작용 항을 투입하였다.

$\mathrm{F}$ 값은 유의확률이 .000 로 통계적으로 유의한 것으로 나타났으며 이는 회귀식의 타당성을 의미한다. 또한 분석결과 4 단계의 변화량에 따른 설명력 $\mathrm{R}^{2}$ 값이 1 3 단계에서 점차 증가하고 있기 때문에 조절효과가 존재하는 것으로 분석되었다. 조절변수인 가치일치성의 직접 조절효과는 3 단계에서 $R^{2}$ 값이 .572 로 가치일치성 $(\beta=.535, p=.000)$ 은 유의한 정(+)의 방향으로 나타났으며, $\mathrm{R}^{2}$ 값의 변화량은 4 단계에서도
점차 증가하였다. 이러한 결과는 개인 창의성이 지식공유에 영향을 미치는 과정에서 가치일치성과 상호작용하면서 지식공유를 촉진 시키고 있음을 의미한다.

가치일치성의 조절효과에 대한 가설검증을 위하여 4 단계 모형에서 개인 창의성의 하위요인과 가치일치성을 곱한 상호작용 항을 투입하였다. 그 결과 $\mathrm{R}^{2}$ 값은 .578 로 3 단계 모형에 비해 설명력이 .006 증가하였다. 개인 창의성의 하위요인인 감성지능은 가치일치성과 긍정적으로 상호작용 효과를 나타냈다. 그러나 전문성과 내적동기부여는 통계적으로 유의하지 않은 것으로 나타났다. 따라서 조직구성원의 개인 창의성과 지식공유의 관계에서 가치일치성의 조절효과 가설은 부분적으로 수용되었다.

Table 5: Moderating Effect of Value Congruence on Innovation Behavior

\begin{tabular}{|c|c|c|c|c|c|c|c|}
\hline \multirow{2}{*}{\multicolumn{2}{|c|}{ Variables }} & \multicolumn{5}{|c|}{ Innovation Behavior (B) } & \multirow{2}{*}{ VIF } \\
\hline & & Step 1 & Step 2 & Step 3 & Step 4 & $\mathbf{t}$ & \\
\hline \multirow{9}{*}{ Control Variables } & (Constant) & & & & & 1.933 & \\
\hline & Gender & -.102 & .050 & .042 & .030 & .755 & 1.300 \\
\hline & Marital Status & .052 & .012 & .031 & .012 & .248 & 1.861 \\
\hline & Age & .056 & .010 & .013 & -.002 & -.034 & 2.231 \\
\hline & Education & .147 & .002 & -.010 & -.044 & -1.159 & 1.193 \\
\hline & Working Years & -.028 & .023 & .021 & .023 & .454 & 2.161 \\
\hline & Number of Employees & .045 & -.016 & .013 & .009 & .229 & 1.221 \\
\hline & Type of Business & -.018 & .033 & .005 & .016 & .379 & 1.401 \\
\hline & Working Organization & -.047 & -.020 & -.014 & .005 & .111 & 1.374 \\
\hline \multirow{3}{*}{$\begin{array}{l}\text { Independent Variable } \\
: \text { Individual Creativity }\end{array}$} & $\begin{array}{l}\text { Professionalism } \\
\qquad(\mathrm{I}-1)\end{array}$ & & .444 & .428 & .868 & $5.037^{* * *}$ & 2.481 \\
\hline & $\begin{array}{l}\text { Emotional Intelligence } \\
\qquad(\text { I -2) }\end{array}$ & & .275 & .212 & -.071 & -.487 & 1.618 \\
\hline & $\begin{array}{c}\text { Internal Motivation } \\
\text { ( I -3) }\end{array}$ & & .212 & .184 & .550 & $3.502^{* * *}$ & 2.315 \\
\hline Moderationg Variables & Value Congruence(III) & & & .198 & .189 & $4.568^{* * *}$ & 1.416 \\
\hline \multirow{3}{*}{ Interaction Terms } & $(\mathrm{I}-1 * \mathrm{III})$ & & & & .447 & $2.469^{*}$ & 2.972 \\
\hline & ( I -2*III) & & & & .311 & $2.026^{*}$ & 1.378 \\
\hline & ( I -3*III) & & & & .387 & $2.308^{*}$ & 2.151 \\
\hline \multicolumn{2}{|c|}{$\mathrm{R}^{2}$} & .039 & 593 & .623 & .653 & \multirow{4}{*}{\multicolumn{2}{|c|}{.653}} \\
\hline \multicolumn{2}{|c|}{ Adjusted $\mathrm{R}^{2}$} & .013 & .578 & .608 & .635 & & \\
\hline \multicolumn{2}{|c|}{$\Delta \mathrm{R}^{2}$} & .039 & .554 & .030 & .030 & & \\
\hline \multicolumn{2}{|c|}{$\mathrm{F}$} & 1.486 & $38.469^{* * *}$ & $39.836^{*}$ & $35.347^{* * *}$ & & \\
\hline
\end{tabular}

$* \mathrm{p}<.05 * * * \mathrm{p}<.001$ 
<가설 $1>$ 에 대한 분석결과의 의미를 논의하면 다음과 같다. 가치일치성이 개인 창의성과 지식공유 간의 관계를 정적(+)으로 조절하는가 여부를 밝히는 가설이다. 그러나 검증 결과 개인 창의성의 세 가지 하위요인인 전문성, 감성지능, 내적동기부여와 지식공유 간의 관계에서 감성지능 만이 가치일치성의 조절효과가 있음이 밝혀졌다. 즉, 개인 창의성이 높으며, 구성원들이 가치일치를 높게 지각할수록 지식공유가 높아진다는 것이다. 또한 가치일치성은 조직 내의 상사지원 및 동료지원에 따라, 개인 창의성이 지식공유에 미치는 영향은 달라질 수 있다. 개인 창의성과 가치일치성의 상호작용을 통해 가치일치성이 높으면 감성지능이 높아져 지식공유가 활성화됨을 의미한다.

<가설 2> 개인 창의성과 혁신행동 간의 관계를 가치일치성이 조절할 것이다. 라는 가설을 검증하기 위하여 <Table 5>와 같이 위계적 회귀분석을 실시하였다. 3 단계 모형은 개인 창의성과 지식공유 간의 관계에서 가치일치성의 조절효과를 검증하기 위해, 개인 창의성의 하위차원과 가치일치성을 곱한 상호작용 항을 투입하였다.

$\mathrm{F}$ 값은 유의확률이 .000 로 통계적으로 유의한 것으로 나타났으며 이는 회귀식의 타당성을 의미한다. 또한 분석결과 4 단계의 변화량에 따른 설명력 $\mathrm{R}^{2}$ 값이 1 3 단계에서 점차 증가하고 있기 때문에 조절효과가 존재하는 것으로 분석되었다. 조절변수인 가치일치성의 직접 조절효과는 3 단계에서 $\mathrm{R}^{2}$ 값이 .623 로 가치일치성( $\left.\beta=.198, \mathrm{p}=.000\right)$ 은 유의한 정(+)의 방향으로 나타났으며, R2값의 변화량은 4 단계에서도 점차 증가하였다. 이러한 결과는 개인 창의성이 혁신행동에 영향을 미치는 과정에서 가치일치성과 상호작용 하면서 혁신행동을 촉진 시키고 있음을 의미한다. 가치일치성의 조절효과에 대한 가설검증을 위하여 4 단계 모형에서 개인 창의성의 하위요인과 가치일치성을 곱한 상호작용 항을 투입하였다. 그 결과 $\mathrm{R}^{2}$ 값은 .653 으로 3 단계 모형에 비해 설명력이 .030 증가하였다. 개인 창의성의 하위요인인 전문성, 감성지능, 내적동기부여는 가치일치성과 긍정적으로 상호작용 효과를 나타냈다. 따라서 조직구성원의 개인 창의성과 혁신행동의 관계에서 가치일치성의 조절효과 가설은 모두 수용되었다.

<가설 2>에 대한 분석결과의 의미를 논의하면 다음과 같다. 가치일치성이 개인 창의성과 혁신행동 간의 관계를 정적(+)으로 조절하는가 여부를 밝히는 가설이다. 그러나 검증 결과 개인 창의성의 세 가지 하위요인인 전문성, 감성지능, 내적동기부여와 혁신행동 간의 관계에서 전문성, 감성지능, 내적동기부여가 가치일치성의 조절효과가 있음이 밝혀졌다. 즉, 개인 창의성이 높으며, 구성원들이 가치일치를 높게 지각할수록 혁신행동이 높아진다는 것이다. 또한 가치일치성은 조직 내의 상사지원 및 동료지원에 따라 개인 창의성이 혁신행동에 미치는 영향은 달라질 수 있다. 개인 창의성과 가치일치성의 상호작용을 통해 가치일치성이 높으면 전문성, 감성지능, 내적동기부여가 높아져 혁신행동이 활성화됨을 의미한다.

\section{6. 결론}

\section{1. 요약}

이 연구는 개인 창의성이 팀 및 조직 의사결정의 핵심이 되는 지식공유와 혁신행동에 미치는 영향력에 있어서 가치일성의 조절효과를 분석하는데 목적이 있다. 기존 연구에서는 지식공유와 혁신행동을 함께 고려하여 두 변수를 매개변수 또는 종속변수로서 함께 검토한 연구들이 일부 있었지만, 주로 지식공유와 혁신행동은 별개로 연구되는 경우가 많았고, 지식공유는 주로 선행요인, 혁신행동은 후행요인으로 분류되었다. 예를 들어, 지식공유가 창의성에 영향을 미치거나, 창의성이 혁신행동에 영향을 미치는 연구가 주를 이루었다. 그러나 본 연구에서는 창의성을 원인변수로 하여 결과변수로서 지식공유와 혁신행동을 함께 고려하였다는 점에서 차별점이 있다. 또한 개인 창의성과 가치일치성의 시너지효과를 검토하였다는 점에서 본 연구의 기여도는 뚜렷하다. 연구결과 가치일치성은 개인 창의성이 지식공유 및 혁신 행동에 미치는 영향을 조절하였다.

연구결과 팀 및 조직은 개인 창의성을 토대로 지식공유가 이루어질 때 추상적 사고와 추론이 가능한 발전적인 대안을 더 잘 만들어 낼 수 있다는 점이 입증되었다. 또한 개인 창의성을 기반으로 한 의사결정 프로세스에 능숙한 팀 및 조직은 혁신적인 팀 분위기를 창출하고 유지할 수 있었다. 즉, 개인 창의성이 수반된 의사결정 프로세스를 통해 지식공유 분위기가 형성되고, 혁신행동이 지속될 수 있음을 확인했다.

또한 가치일치성 여부는 개인 창의성이 지식공유와 혁신행동에 긍정적 영향을 미치는 데 있어서 결정적인 조절역할을 수행하는 것이 입증되었다. 즉, 개인과 조직의 가치일치가 높은 환경에서는 개인 창의성이 조직의 혁신과 지식의 확산에 더욱 큰 영향을 발휘할 수 있게 된다.

\section{2. 연구의 학문적 시사점}

다양한 아이디어를 갖는 구성원은 기존의 고착된 사고의 집합을 깨면서 문제에 대한 대체적인 솔루션을 내놓는 데에 뛰어나다. 본 연구결과를 통해 개인 창의성의 가장 중요한 핵심이 밝혀졌을 뿐만 아니라 개인 창의성이 팀 및 조직 전체의 성과와 직접적으로 연관이 있음이 입증되었다.

구체적으로 살펴보면 다음과 같다.

첫째, 개인 창의성과 가치일치성이 시너지효과를 발휘하여 지식공유에 매우 큰 영향을 미쳤다. 즉, 개인과 조직의 가치가 일치되는 환경에서는 그렇지 않은 경우에 비해 개인 창의성이 더 크게 지식공유 성과에 영향을 미쳤다. 다만 감성지능 측면의 창의성이 가치일치성과 
유의미한 시너지효과를 발휘하는 반면, 전문성과 내적 동기부여 측면의 창의성은 시너지효과가 없었다.

둘째, 개인 창의성과 가치일치성이 시너지효과를 발휘하여 혁신행동에 매우 큰 영향을 미쳤다. 즉, 개인과 조직의 가치가 일치되는 환경에서는 그렇지 않은 경우에 비해 개인 창의성이 더 크게 혁신행동 성과에 영향을 미쳤다.

\section{3. 연구의 실무적 시사점}

본 연구에서는 개인 창의성, 지식공유, 혁신행동, 가치일치성에 대한 구성요소를 정의하고 이들 변수 간의 관련성을 중심으로 검토하였다. 개인 창의성을 작업 환경적 요소로 간주하는 선행 연구와 달리, 본 연구는 개인 창의성을 지식공유와 조직혁신의 중요한 원인으로 파악하고, 조절 요인으로서 가치일치성에 주목하였다. 개인 창의성과 조직과 개인의 가치일치성을 이분법적으로 접근하지 않고 개인 창의성이 가치일치성과 어떤 상호작용효과(시너지효과)를 보이느냐에 따라 조직의 성과(지식공유, 혁신행동)가 달라질 수 있음으로 밝혀내었다. 이러한 의미에서 이 연구는 개인이 혁신적인 조직 및 팀 프로세스에 기여할 수 있도록 개인 창의성을 충분히 발휘할 수 있는 업무 환경을 제공하고 개인과 조직의 가치일치의 중요성을 경영자에게 설득할 수 있는 근거를 제시한다.

\section{4. 연구의 한계점 및 향후과제}

본 연구는 가치일치성을 창의성과 함께 고려한 최초 연구라는 점에서 기존 연구가 부족하므로 몇 가지 한계를 가지고 있으며 이에 따라 향후 추가 연구가 필요하다.

첫째, 설문 측정을 위해 각 문항마다 5 점 척도를 사용함으로써 응답의 편향성을 줄이는 것을 목표로 함으로써 신뢰성과 타당성이 7점 척도에 비해 낮게 나오는 것을 감수하였다. 설문 문항이 많은 관계로 변수별로 문항을 정리하여 질문하게 됨으로써 연구자의 의도를 응답자가 예측할 수 있었던 점에서 실제보다 연구성과가 뚜렷하게 검증되었을 가능성도 존재한다.

둘째, 차후 분석에서는 편상관분석과 공분산분석(ANCOVA)에 의해 외생변수를 최대한 통제한 상태에서 분석함으로써 왜곡 응답을 줄이고 응답자들이 긍정편향으로 답을 하지 못하도록 할 필요성이 있다.

셋째, 향후 연구에서는 각 근무기관별로 더 많은 표본을 추출하는 등 연구대상의 범위를 확장할 경우 일부 기각된 가설검증의 결과가 채택될 가능성도 있다고 본다.
넷째, 향후 연구에서는 창의성, 가치일치성 변수들을 더욱 세분화하여 연구 모형을 정교화한 뒤에 세밀한 검증을 한다면 많은 성과가 있을 것으로 예상된다.

\section{References}

Abrams, L. C., Cross, R., Lesser, E., \& Levin, D. Z. (2003). Nurturing Interpersonal Trust in Knowledge-Sharing Networks. Academy of Management Perspectives, 17(4), 6477.

Amabile, T. M. (1983). The Social Psychology of Creativity: A Componential Conceptualization. Journal of Personality and Social Psychology, 45(2), 357-376.

Amabile, T. M. (1988). From Individual Creativity to Organizational Innovation. In K. Grønhaug, \& G. Kaufmann (Eds.), Innovation: A Cross-Disciplinary Perspective (p. 139-166), Norwegian University Press.

Amabile, T. M., Conti, R., Coon, H., Lazenby, J., \& Herron, M. (1996). Assessing the Work Environment for Creativity. The Academy of Management Journal, 39(5), 1154-1184.

Amabile, T. M., Schatzel, E. A., Moneta, G. B., \& Kramer, S. J. (2004). Leader Behaviors and the Work Environment for Creativity: Perceived Leader Support. The Leadership Quarterly, 15(1), 5-32.

Bandura, A., \& Locke, E. A. (2003). Negative Self-Efficacy and Goal Effects Revisited. Journal of Applied Psychology, 88(1), 87-99.

Bluedorn, A. C., Kalliath, T. J., Strube, M. J., \& Martin, G. D. (1999). Polychronicity and the Inventory of Polychronic Values (IPV) The Development of an Instrument to Measure a Fundamental Dimension of Organizational Culture. Journal of Managerial Psychology, 14(3/4), 205-231.

Bock, G. W., Zmud, R. W., Kim, Y. G., \& Lee, J. N. (2005). Behavioral Intention Formation in Knowledge Sharing: Examining the Roles of Extrinsic Motivators, SocialPsychological Factors, and Organizational Climate. MIS Quarterly, 29(1), 87-111.

Cable, D. M., \& Judge, T. A. (1996). Person-organization fit, job choice decisions, and organizational entry. Organizational behavior and human decision processes, 67(3), 294-311.

Cazier, J. A., Shao, B. B., \& Louis, R. D. (2007). Sharing Information and Building Trust Through Value Congruence. Information Systems Frontiers, 9(5), 515-529.

Chatman, J. A. (1989). Improving Interactional Organizational Research: A Model of Person-Organization Fit. Academy of Management Review, 14(3), 333-349.

Daellenbach, U. S., McCarthy, A. M., \& Schoenecker, T. S. (1999). Commitment to Innovation: The Impact of Top Management Team Characteristics. R\&D Management, 29(3), 199-208.

Davenport, S., Davies, J., \& Grimes, C. (1998). Collaborative Research Programmes: Building Trust From Difference. Technovation, 19(1), 31-40.

Deci, E. L., Vallerand, R. J., Pelletier, L. G., \& Ryan, R. M. (1991). Motivation and Education: The Self-Determination Perspective. Educational Psychologist, 26(3-4), 325-346.

Farmer, S. M., Tierney, P., \& Kung-Mcintyre, K. (2003). Employee 
Creativity in Taiwan: An Application of Role Identity Theory. Academy of Management Journal, 46(5), 618-630.

Farr, J. L., \& Ford, C. M. (1990). Individual innovation. In M. A. West \& J. L. Farr (Eds.), Innovation and creativity at work: Psychological and organizational strategies: 63-80. Chichester, UK: Wiley.

Gupta, A. K., \& Govindarajan, V. (2000). Knowledge Management's Social Dimension: Lessons From Nucor Steel. MIT Sloan Management Review, 42(1), 71-80.

Hunt, S. D., Wood, V. R., \& Chonko, L. B. (1989). Corporate Ethical Values and Organizational Commitment in Marketing. Journal of Marketing, 53(3), 79-90.

Janssen, O. (2000). Job Demands, Perceptions of Effort-Reward Fairness and Innovative Work Behaviour. Journal of Occupational and Organizational Psychology, 73(3), 287-302.

Jung, D., Yammarino, F. J., \& Lee, J. K. (2009). Moderating Role of Subordinates' Attitudes on Transformational Leadership and Effectiveness: A Multi-Cultural and Multi-Level Perspective. The Leadership Quarterly, 20(4), 586-603.

Kanter, R. M. (1988). Three Tiers for Innovation Research. Communication Research, 15(5), 509-523.

Kleysen, R. F., \& Street, C. T. (2001). Toward a Multi-Dimensional Measure of Individual Innovative Behavior. Journal of Intellectual Capital, 2(3), 284-296.

Lee, J. P., \& Park, K. H. (2019). The Effect of Personal Creativity on Knowledge Sharing and Innovation Behavior: Focused on Retail Workers. Journal of Distribution Science, 17(10), 93-105.

Meglino, B. M., \& Ravlin, E. C. (1998). Individual Values in Organizations: Concepts, Controversies, and Research. Journal of Management, 24(3), 351-389.

Morrison, E. W., \& Phelps, C. C. (1999). Taking Charge At Work: Extrarole Efforts to Initiate Workplace Change. Academy of Management Journal, 42(4), 403-419.

Oldham, G. R., \& Cummings, A. (1996). Employee Creativity: Personal and Contextual Factors at Work. Academy of Management Journal, 39(3), 607-634.

Ostroff, C., Shin, Y., \& Kinicki, A. J. (2005). Multiple Perspectives of Congruence: Relationships Between Value Congruence and Employee Attitudes. Journal of Organizational Behavior: The International Journal of
Industrial, Occupational and Organizational Psychology and Behavior, 26(6), 591-623.

Pirola-Merlo, A., \& Mann, L. (2004). The Relationship Between Individual Creativity and Team Creativity: Aggregating Across People and Time. Journal of Organizational Behavior, 25(2), 235-257.

Riege, A. (2005). Three-Dozen Knowledge-Sharing Barriers Managers Must Consider. Journal of Knowledge Management, 9(3), 18-35.

Rousseau, D. (1995). Psychological Contracts in Organizations: Understanding Written and Unwritten Agreements. Sage Publications.

Scott, S. G., \& Bruce, R. A. (1994). Determinants of Innovative Behavior: A Path Model of Individual Innovation in the Workplace, The Academy of Management Journal, 37(3), 580607.

Shalley, C. E. (1995). Effects of Coaction, Expected Evaluation, and Goal Setting on Creativity and Productivity. Academy of Management Journal, 38(2), 483-503.

Spreitzer, G. M. (1995). Psychological Empowerment in the Workplace: Dimensions, Measurement, and Validation. Academy of Management Journal, 38(5), 1442-1465.

Spreng, R. A., MacKenzie, S. B., \& Olshavsky, R. W. (1996). A Reexamination of the Determinants of Consumer Satisfaction. Journal of Marketing, 60(3), 15-32.

Thomas, K. W., \& Velthouse, B. A. (1990). Cognitive Elements of Empowerment: An "Interpretive" Model of Intrinsic Task Motivation. Academy of Management Review, 15(4), 666-681.

Tierney, P., \& Farmer, S. M. (2002). Creative Self-Efficacy: Its Potential Antecedents and Relationship to Creative Performance. Academy of Management Journal, 45(6), 1137-1148.

Wang, S., \& Noe, R. A. (2010). Knowledge Sharing: A Review and Directions for Future Research. Human Resource Management Review, 20(2), 115-131.

West, M. A., \& Farr, J. L. (1989). Innovation at Work: Psychological Perspectives. Social Behaviour, 4(1), 15-30.

Woodman, R. W., Sawyer, J. E., \& Griffin, R. W. (1993). Toward a Theory of Organizational Creativity. Academy of Management Review, 18(2), 293-321. 